\title{
A educação no pensamento de Karl Marx
}

\section{Education in the thought of Karl Marx}

Fernanda Quatorze Voltas Saul é mestre pelo Programa de PósGraduação em Educação da UNINOVE.

Contato: fernanda14voltas@hotmail.com

\section{Resumo}

Ao lado de Max Weber e Émile Durkheim, Karl Marx é considerado um dos pensadores que mais influenciaram os teóricos sociais da modernidade no ocidente. Embora Marx não tenha tido a intenção de sistematizar uma teoria sobre a educação, algumas elaborações sobre o tema podem ser encontradas ao longo de sua obra. Dessa forma, o presente trabalho tem a intenção de refletir acerca da visão de Marx sobre a educação e as suas possíveis interpretações a partir de duas correntes marxistas distintas: as teorias da reprodução e da resistência. Dentre as possíveis interpretações sobre o pensamento educacional de Marx, o texto defende aquela que reconhece que a Escola não é apenas um espaço de reprodução ideológica na sociedade capitalista, mas é também, por contradição, um espaço de luta e resistência ao pensamento hegemônico dominante. Palavras-chave: Karl Marx; ideologia; educação.

\section{Abstract}

Along with Max Weber and Emile Durkheim, Karl Marx is considered one of the thinkers who most influenced social theorists of modernity in the West. Although Marx did not have the intention to articulate a theory of education, some elaborations on the theme can be found throughout his work. Thus, this paper intends to reflect on the vision of Marx on education and its possible interpretations starting from two distinct Marxist chains: the theories of reproduction 
and resistance. Among the possible interpretations of the educational thought of Marx, the text defends the one that recognize that the School is not just a space for ideological reproduction in capitalist society, but also, by contradiction, a space of struggle and resistance to the dominant hegemonic thinking. Keywords: Karl Marx; ideology; education.

\section{Contexto histórico e social do pensamento marxista}

Karl nasceu em Trèves, na Renânia, em maio de 1818 e morreu em 1883, em Londres. Ao lado de Émile Durkheim (1858-1917) e de Max Weber (1864-1920), é considerado um dos maiores pesadores que influenciaram os teóricos sociais da modernidade no ocidente. Partindo-se do pressuposto que toda teoria social é filha de seu tempo, o pensamento de Marx deve ser compreendido dentro do contexto histórico e social em que foi produzido. Podese localizá-lo, portanto, no século XIX, período de consolidação do capitalismo industrial, subsequente à Revolução Industrial ocorrida na Inglaterra no século XVIII.

O capitalismo, desde a sua origem, criou condições materiais para o surgimento de duas classes sociais contraditórias e de interesses inconciliáveis: a burguesia e o proletariado. Nesse contexto, a propriedade privada dos meios de produção encontrava-se nas mãos da burguesia, que já produzia a maisvalia pela exploração da classe operária. Esta, não sendo proprietária dos meios de produção, só tinha para vender a sua força de trabalho. Por consequência, tinha seu trabalho extremamente explorado e, em troca, recebia um salário que garantia apenas a manutenção de sua subsistência material.

As contradições geradas no interior do capitalismo, associadas às condições degradantes de trabalho a que estava submetida a grande massa de assalariados industriais, possibilitou o surgimento, também nesse período, dos primeiros movimentos sindicais na Europa.

De acordo com o materialismo histórico, as bases econômicas, aliadas ao progresso tecnológico, sobretudo na área industrial, criaram as condições para o surgimento de novas teorias que tentavam explicar e/ou justificar a realidade concreta e as contradições inerentes ao capitalismo industrial. 
Dessa forma, o referido período possibilitou a produção do pensamento positivista, criado pelo filósofo francês Auguste Comte (1789-1854). A ideia de progresso natural e linear intrínseca ao seu discurso científico foi apropriada pela burguesia, que viu nela a justificativa para as contradições do modo de produção capitalista.

É nesse contexto que surge a teoria marxista. De maneira geral, Marx critica os filósofos da tradição ocidental, por considerá-los demasiado idealistas, alheios em relação às condições históricas concretas. Mesmo assim, Hegel (1770-1831) é um referencial importante para sua obra, principalmente no que se refere aos conceitos de dialética (real como permanente devir) e historicidade (processo de transformação da realidade).

Marx considera, porém, que Hegel colocou a dialética às avessas, ao construir sua teoria com base idealista. Para ele, o materialismo histórico e dialético coloca a dialética "com os pés no chão", aplicando-a à realidade concreta e histórica. (GRESPAN, 2002, p. 28).

\section{Trabalho manual $x$ trabalho intelectual no capitalismo}

Para Karl Marx, o homem é um ser da natureza, resultado de um longo processo de evolução biológica. Além disso, é também um ser da práxis, ou seja, por meio da ação-reflexão transforma o mundo e cria sua própria existência.

Para a teoria marxista, o trabalho é uma forma de relação social especificamente humana, que diferencia o homem dos demais animais da natureza. É por meio do trabalho que o homem transforma a natureza, tornando-se um ser social e histórico.

Em Marx, o trabalho é a categoria fundante da humanização, embora na sociedade capitalista seja causa de desumanização (ANDRADE FILHO, 1999, p. 74). Isso se justifica pelo fato de que, nessas sociedades, o labor humano encontra-se sob o jugo da divisão social do trabalho e da propriedade privada dos meios de produção.

A divisão social do trabalho não é característica exclusiva do capitalismo, tendo existido ao longo da história como, por exemplo, em algumas sociedades primitivas tribais. Nessas, porém, tal divisão dava-se de forma mais ou menos "natural", pois os trabalhos eram divididos coletivamente, segundo habilidades, aptidões físicas e demandas de execução. Nas sociedades 
capitalistas, entretanto, a propriedade privada dos meios de produção e a divisão social do trabalho promovem a separação entre atividade intelectual e atividade manual. Dessa maneira, o operário é alienado de seu trabalho, pois o produto do mesmo é uma mercadoria que não lhe pertence, e na qual não se reconhece:

\begin{abstract}
[...] com a divisão do trabalho fica dada a possibilidade, mais ainda, a realidade, de que a atividade espiritual e material - a fruição e o trabalho, a produção e o consumo - caibam a indivíduos diferentes; e a possibilidade de não entrarem esses elementos em contradição reside apenas unicamente no fato de que a divisão do trabalho seja novamente superada (MARX; ENGELS, 1979, p. 45 -46).
\end{abstract}

Com a separação compulsória e violenta dos produtores diretos de seus meios de produção, o trabalhador é constrangido a vender sua força de trabalho para conseguir os meios necessários para sua sobrevivência. 0 sentido do trabalho passa a ser apenas a garantia das condições urgentes da vida material. Assim, o proletário é desumanizado e consumido por um trabalho que não é vida, o "trabalho morto", na visão de Marx. Nessa perspectiva, a vida do homem só acontece nos momentos externos ao trabalho.

É preciso salientar, entretanto, que, nesse sistema, não é apenas o trabalhador que é desumanizado e alienado de seu trabalho. 0 mesmo ocorre em relação aos proprietários dos meios de produção. Na divisão social do trabalho, esses dirigem apenas intelectualmente a produção, portanto também não se reconhecem no produto de seu trabalho. Ao promoverem a desumanização do proletário se desumanizam, por consequência.

\section{Educação e Ideologia}

0 materialismo histórico e dialético de Karl Marx não teve como pretensão sistematizar uma teoria sobre a educação. Ainda assim, é possível encontrar apontamentos do filósofo sobre o tema em alguns extratos intermitentes ao longo de sua obra. Nesse sentido, Ferge (2001, p. 122) esclarece que: "Os elementos de uma concepção marxista de educação começam a surgir na década de 1840, em muitas obras de Marx e Engels (e.g. O Capital, cap. XIII; A ideologia Alemã, vol. I, parte I; Crítica ao Programa de Gotha, IV e Princípios do Comunismo, de Engels)". Para além dos registros escritos, a temática da educação também foi tratada por Marx na ocasião de seus pronunciamentos durante a Primeira Internacional', promovida pela Associação Internacional dos Trabalhadores (AIT).
1. "A Primeira Internacional foi uma federação internacional das organizações da classe trabalhadora de vários países da Europa Central e Ocidental, onde o movimento operário estava renascendo na década de 1860. [...] Embora tenha sido fundada pelos esforços espontâneos dos trabalhadores de Londres e Paris, que manifestavam sua solidariedade com o levante nacional polonês, de 1863 , Marx (de 1864 a 1872) e Engels (de 1870 a 1872) iriam desempenhar o papel chave em sua liderança)" (JOHNSTONE, 2001, p. 195). 
Em sua obra, Marx localiza a educação no âmbito da superestrutura, ou seja, no universo propriamente da cultura. Dessa forma, esta se encontra sujeita à influência da infraestrutura, que reflete o conjunto das condições econômicas concretas, relacionadas ao desenvolvimento das forças produtivas de uma dada sociedade, num determinado espaço e tempo histórico. Assim:

A produção de ideias de representações, da consciência está, de início, diretamente entrelaçada com a atividade material e com o intercâmbio material dos homens, com a linguagem da vida real. 0 representar, o pensar, [a educação], o intercâmbio espiritual dos homens, aparece aqui como emanação direta de seu comportamento material. [...] Não é a consciência que determina a vida, mas a vida que determina a consciência (MARX; ENGELS, 1979, p.36).

Para Marx, é também na esfera da superestrutura, por meio da ideologia, que as burguesia atua para garantir sua hegemonia, seu poder sobre a classe proletária. Em consonância com esse pensamento, Marilena Chauí esclarece que:

\footnotetext{
(...) a história é o real, e o real é o movimento incessante pelo qual os homens, em condições que nem sempre foram escolhidas por eles, instauram um modo de sociabilidade e procuram fixá-lo em instituições determinadas. Além de procurar fixar seu modo de sociabilidade através de determinadas instituições, os homens produzem ideias ou representações pelas quais procuram explicar e compreender sua própria vida individual, social, suas relações com a natureza e com o sobrenatural. Em sociedades divididas em classes (e também em castas), nas quais uma das classes explora e domina as outras, essas explicações ou essas ideias e representações serão produzidas e difundidas pela classe dominante para legitimar e assegurar seu poder econômico, social e político. Por esse motivo, essas ideias ou representações tenderão a esconder dos homens o modo real como suas relações sociais foram produzidas e a origem das formas sociais de exploração econômica e de dominação política. Esse ocultamento da realidade social chama-se ideologia (2008, p. 24).
}

Pode-se dizer que as concepções de infraestrutura, superestrutura e ideologia, ancoradas na filosofia marxista, serviram de base para as "teorias da reprodução" 2 para as quais as escolas são agências de dominação cultural e de reprodução ideológica das classes dominantes à serviço da desarticulação e apaziguamento das lutas de classes. Nessa perspectiva, a educação teria a função de manter o status quo, de afirmar as desigualdades econômicas e sociais da sociedade capitalista.

2. Assim denominadas por Giroux (1986). Maiores detalhes sobre tais teorias e os seus principais representantes serão apresentados no item 5 deste texto. 
Porém, como veremos adiante, nem todos os pensadores que estruturaram suas teorias a partir da obra de Marx compartilham dessa posição em relação ao papel e às possibilidades da educação no contexto contraditório das sociedades divididas em classes.

\section{A educação na visão de Marx}

Nas Instruções aos Delegados do Conselho Central Provisório da AlT, de 1868, Marx assim se manifesta:

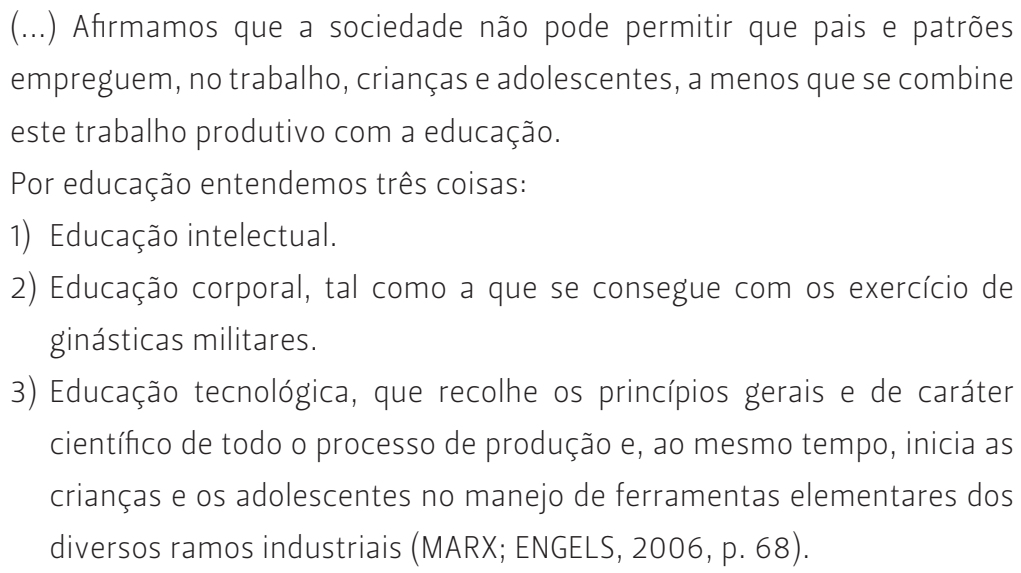

Para Marx, a educação deve estar integrada ao trabalho produtivo desde a infância. Isso não deve ser entendido como apologia à exploração do trabalho infantil. É que para esse filósofo, o homem constrói sua humanidade em sua práxis no mundo, por meio do trabalho. Ao transformar o mundo, também se transforma. Pode-se dizer que o trabalho é a categoria fundante da humanização, para Marx, e também um "princípio educativo" (LOMBARDI, 2008).

Nessa perspectiva, a educação associada ao trabalho produtivo, tem a função de reintegrar o trabalho intelectual ao trabalho manual (concepção e execução), separados pela divisão social do trabalho nas sociedades capitalistas. A intenção é que o trabalhador tenha uma compreensão integral do processo produtivo e não esteja alienado do mesmo. Isso também pode ser visto como uma possibilidade de superar a ruptura entre a ciência e o trabalho, típica da produção industrial. Lombardi (2008, p. 11) destaca que a teoria marxista entende que: "com o trabalho produtivo, a educação deveria possibilitar o acesso aos conhecimentos historicamente produzidos pela humanidade, em seus aspectos filosófico, científico, literário, intelectual, moral, físico, industrial e cívico". 
No bojo dessa filosofia, a educação está associada ao conceito de omnilateralidade e deve contribuir para o desenvolvimento integral do ser humano, no sentido de promover o acesso/ produção de cultura e a construção de saberes. Sobre a referida concepção, Manacorda (1991, p. 81) esclarece que:

\begin{abstract}
A omnilateralidade é, portanto, a chegada histórica do homem a uma totalidade de capacidades produtivas e, ao mesmo tempo, a uma totalidade de capacidades de consumo e prazeres, em que se deve considerar, sobretudo, o gozo daqueles bens espirituais [inclusa a educação], além dos materiais, e dos quais o trabalhador tem estado excluído em consequência da divisão do trabalho.
\end{abstract}

É importante salientar que, para Marx, a educação politécnica caminha lado a lado com a concepção de omnilateralidade. É o próprio desenvolvimento do capitalismo (e suas contradições) que cria bases para a sua implementação. Em consonância com esse entendimento, Lombardi (2008, p. 14) aponta que:

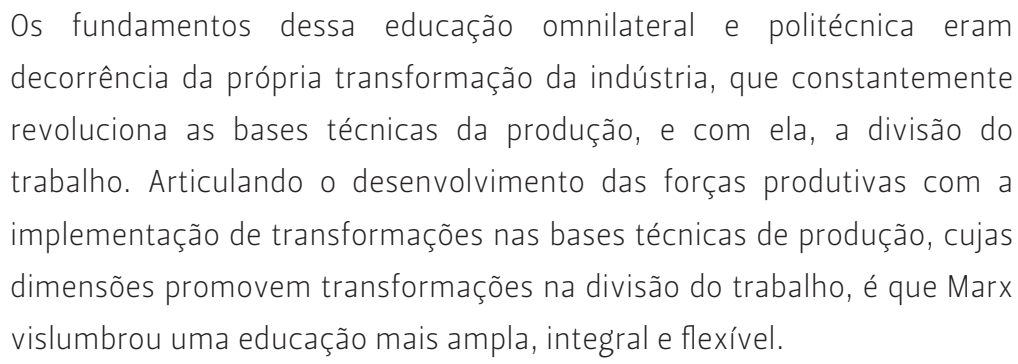

Em contraposição à visão capitalista, o marxismo entende que a associação do trabalho à educação politécnica não tem como objetivo principal o aumento da produtividade e do lucro, mas está relacionada à questão do desenvolvimento pleno das capacidades humanas, ou seja, à construção do homem omnilateral³.

Marx reconhece, porém, que tal educação só é possível em uma sociedade onde sejam extintas a propriedade privada dos meios de produção e a divisão social do trabalho, típicas do capitalismo, ou seja, em uma sociedade comunista.

É o próprio capitalismo, por meio do acirramento de suas contradições internas que criará as condições materiais para o surgimento da sociedade socialista. A riqueza gerada pelo desenvolvimento da totalidade das forças produtivas capitalistas, em conflito com a extrema pobreza e exploração dos trabalhadores, criará condições concretas para uma revolução da classe operária e para a consequente implementação do socialismo, e por fim, do comunismo.
3. Homem cujas capacidades corporais, intelectuais e criativas encontram-se potencialmente desenvolvidas. 
Em suma, o desenvolvimento do homem integral, em que a omnilateralidade se manifeste concretamente, pressupõe a existência de uma práxis educativa que:

\footnotetext{
[... ligando-se ao desenvolvimento real da sociedade, realize a nãoseparação dos homens em esferas alheias, estranhas umas às outras e contrastantes, ou seja, uma práxis educativa que se funde sobre um modo de ser que seja o mais possível associativo e coletivo no seu interior e, ao mesmo tempo, unido à sociedade real que o circunda (MANACORDA, 1991, p. 75).
}

Além desses aspectos, Marx defende que a educação deve ser pública, compulsória, gratuita e laica, "que assegure a abolição dos monopólios culturais ou do conhecimento e das formas privilegiadas de instrução" (FERGE, 2001, p. 122) e garanta o acesso das crianças da classe operária ao ensino.

\section{Interpretações do pensamento marxista em Educação: as teorias da reprodução e da resistência}

Ao longo do tempo a filosofia marxista tem sido referência para alguns teóricos interessados em debater o papel social da educação, a partir do pressuposto da realidade da luta de classes no contexto das sociedades capitalistas.

Em sua obra Teoria Crítica e Resistência em Educação: para além das teorias de reprodução, Giroux (1986) aponta para a existência de duas importantes correntes de pensamento que se propõem a discutir a educação desde o ponto de vista da teoria de Marx. São elas: as Teorias da Reprodução e as Teorias da Resistência.

Para o autor, as teorias da reprodução apresentam a característica comum de compreenderem a escola como uma instituição à serviço da reprodução social e cultural do pensamento hegemônico. Ao naturalizar em seu interior as lógicas da dominação e da desigualdade, por meio de mecanismos de reprodução ideológica, a escola desempenharia um significativo papel na conservação de uma ordem social caracterizada por relações de poder assimétricas e por variadas formas de exploração econômica e social, cuja manutenção interessa somente às classes dominantes.

Giroux (1986, p. 107) esclarece que, a partir do referencial marxista, tais teorias podem ser compreendidas como aquelas que: 


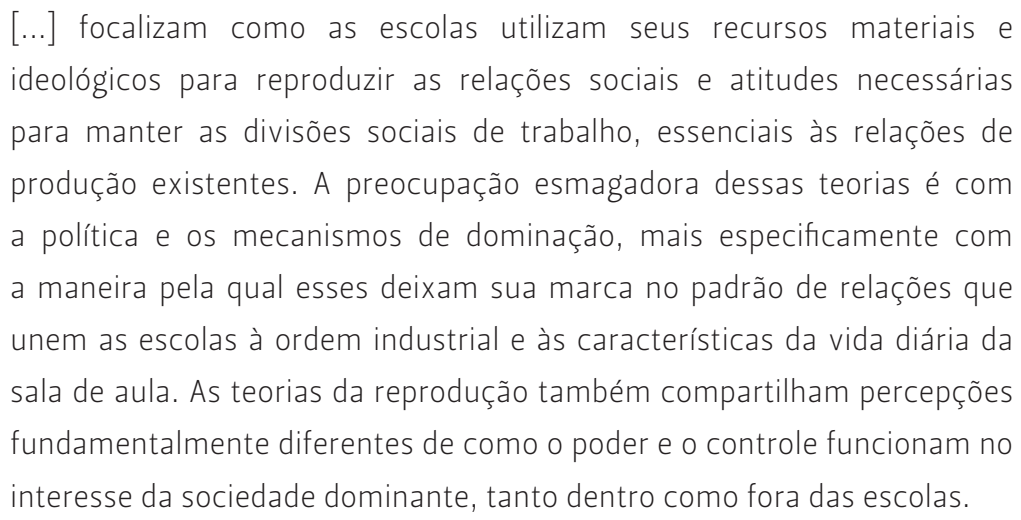

As teorias da reprodução, segundo Stanley (1992), surgiram a partir da década de 1970. Em seus estudos, Giroux (1986) destaca como importantes representantes dessas teorias os autores: Louis Althusser, Samuel Bowles, Herbert Gintis, Pierre Bourdieu e Basil Bernstein.

É importante salientar que, ao desvelar criticamente os mecanismos de reprodução cultural e social subjacentes aos processos educativos, tais teorias deram significativas contribuições à análise da função social da escola. Isso porque permitiram combater e desmitologizar uma concepção liberal e conservadora que defende a escola como uma instituição "neutra", responsável apenas pela transmissão de conhecimentos e habilidades necessárias para adaptação do homem a uma vida harmônica em sociedade.

Por outro lado, ao se analisar os limites conceituais das teorias da reprodução, fica evidente o seu determinismo unilateral, que desconsidera qualquer possibilidade de resistência humana frente às realidades contraditórias da estrutura social, historicamente produzidas. Embora façam uma denúncia contundente dos processos de reprodução mediados pela escola, estas teorias tendem a se esgotar em uma análise pouco dialética, enraizada em um "pessimismo radical" (STANLEY, 1992).

Essas e outras críticas às teorias da reprodução começaram a ganhar vulto a partir da década de 1980. Nesse contexto, Giroux (1986) aponta para o surgimento de vários estudos educacionais, ancorados no ideário marxista, que integram os importantes avanços conceituais alavancados por tais teorias, mas tentam romper com os limites analíticos de seu determinismo: as teorias da resistência.

Os teóricos da resistência assumem a perspectiva dialética como pressuposto para as suas análises da realidade. Sem negar 
os processos de acomodação ao pensamento hegemônico, decorrentes dos mecanismos de reprodução social e cultural, buscam explicitar a existência não só de ajustamentos, mas também de conflitos e contradições entre a estrutura e a ação humana no ambiente escolar.

Nessa perspectiva, a escola é entendida como um terreno em disputa, uma arena de lutas políticas e ideológicas na qual há espaço para a contestação e para a produção de utopias contra-hegemônicas. Para Giroux (1986, p. 157):

\begin{abstract}
As escolas produzem formações sociais em torno de exploração de classes, gêneros e raça, mas ao mesmo tempo contém pluralidades contraditórias que geram possibilidades tanto para mediação quanto para a contestação das ideologias e práticas dominantes. Efetivamente a escola nem é um baluarte da dominação, nem um lócus de revolução; assim, ela contém espaços ideológicos e materiais para o desenvolvimento de pedagogias radicais.
\end{abstract}

Em linha com as teorias da resistência, destacam-se os estudos desenvolvidos por Henry Giroux, Michael Apple, Paul Willis, Philip Corrigan, Paul Olson e pelo educador brasileiro Paulo Freire. Stanley (1992) reconhece que: "De fato, o trabalho inicial de Freire foi o precursor do que depois veio a se chamar de teoria da resistência" (p. 101, tradução nossa).

Em seu livro Pedagogia da Autonomia, Freire combate a ideia da suposta neutralidade da prática educativa. Não sendo neutra, a escola pode estar a serviço tanto da reprodução das ideologias dominantes, interessadas na manutenção das variadas formas de desigualdade econômicas e sociais, quanto da construção de uma visão crítica, capaz de sensibilizar o homem quanto à percepção de seus condicionamentos históricos e às possibilidades de transformação das realidades opressoras:

\footnotetext{
[... se a educação não pode tudo, alguma coisa fundamental a educação pode. Se a educação não é a chave das transformações sociais, não é também simplesmente reprodutora da ideologia dominante. 0 que quero dizer é que a educação nem é uma força imbatível a serviço da transformação da sociedade, porque assim eu queira, nem tampouco é a perpetuação do "status quo" porque o dominante o decrete. 0 educador e a educadora críticos não podem pensar que, a partir do curso que coordenam ou do seminário que lideram, podem transformar o país. Mas podem demonstrar que é possível mudar. E isto reforça nele ou nela a importância de sua tarefa político-pedagógica (FREIRE, 2008, p. 112).
}

Em sintonia com Freire, Giroux (2006) aponta um dos espaços de mudança possíveis no interior da escola, a ser explorado pelos educadores progressistas: 
0 educador progressista rejeita os valores dominantes impostos à escola porque possui um sonho diferente, porque quer transformar o status quo. Naturalmente, transformar o status quo é muito mais difícil do que mantêlo. [...] o espaço educacional reproduz a ideologia dominante. Contudo é possível, dentro das instituições educacionais, atuar contrariamente aos valores dominantes impostos. A reprodução da ideologia dominante implica necessariamente a ocultação de verdades. 0 desvelamento da realidade está dentro do espaço de mudança possível em que os educadores progressistas e politicamente claros devem atuar. [...] Nessa tarefa, é necessário que os educadores assumam uma postura política que se recuse a reconhecer o mito da neutralidade pedagógica. (GIROUX, 2006 apud FREIRE; MACEDO, 2006, p.75-76)

Ao fazer a opção por essa leitura, acreditamos que a educação traz em si, potencialmente, a tarefa de denunciar a realidade opressora, de desvelar os processos alienantes e as formas de ideologia cotidianamente ocultadas. Ao mesmo tempo, deve assumir o compromisso de anunciar e propor uma nova realidade social, a ser construída por meio de uma práxis humanizadora, organizada coletivamente.

\section{REFERÊNCIAS}

ANDRADE FILHO, F. A. Trabalho: a expressão fundante da humanização. Revista Symposium, n. Especial, p. 73-81, jun. 1999.

CHAUÍ, Marilena. O que é ideologia. 2. ed. São Paulo: Editora Brasiliense, 2008.

FERGE, Zsuzsa. Educação. In: BOTTOMORE, Tom (org.). Dicionário do Pensamento Marxista. Tradução de Waltensir Dutra. Rio de Janeiro: Jorge Zahar Editora, 2001. p. 122.

FREIRE, Paulo. Pedagogia da autonomia: saberes necessários à prática educativa. 37. ed. São Paulo: Paz e Terra, 2008.

FREIRE, Paulo; MACEDO; Donaldo. Alfabetização: leitura do mundo leitura da palavra. São Paulo: Editora Paz e Terra, 2006.

GIROUX, Henry. Teoria Crítica e resistência em Educação: para além das teorias de reprodução. Tradução de Ângela Maria B. Biaggio. Petrópolis: Vozes, 1986. 
GRESPAN, Jorge. A dialética do avesso. Revista Crítica Marxista, Campinas, n. 14, p. 21-44, 2002.

JOHNSTONE, Monty. Internacionais. In: BOTTOMORE, Tom (org.). Dicionário do Pensamento Marxista. Tradução de Waltensir Dutra. Rio de Janeiro: Jorge Zahar Editora, 2001. p. $195-199$.

LOMBARDI, José Claudinei. Educação, ensino e formação profissional em Marx e Engels. In: LOMBARDI, José Claudinei; SAVIANI, Demerval (orgs.). Marxismo e educação: debates contemporâneos. 2. ed. Campinas, 2008. p. 01-38.

MANACORDA, Mario Alighiero. Marx e a pedagogia moderna. Tradução de Newton Ramos de Oliveira. São Paulo: Cortez, 1991.

MARX, Karl; ENGELS, Friedrich. A ideologia alemã. Tradução de José Carlos Bruni e Marco Aurélio Nogueira. São Paulo: Livraria Editora Ciências Humanas, 1979.

MARX, Karl; ENGELS, Friedrich. Textos sobre Educação e Ensino. Tradução de Rubens Eduardo Frias. 5. ed. São Paulo: Centauro Editora, 2006.

STANLEY, William B. Curriculum for utopia: social reconstructionism and critical pedagogy in the postmodern era. Albany: State University of New York Press, 1992.

Recebido em: 14/12/2013

Revisto em: 17/04/2014

Aprovado em:18/04/2014 